\title{
Efficacy and feasibility of G-POEM in management of patients with refractory gastroparesis: a systematic review and meta-analysis
}

\section{(ㄷ)(우우}

\author{
Authors \\ Ichkhanian $^{5}$, Mouen A. Khashab ${ }^{5}$ \\ Institutions \\ 1 Tehran University of Medical Sciences, Tehran, Iran \\ 2 Division of Gastroenterology and Hepatology, Archbold \\ Medical Group/Florida State University, United States \\ 3 Russell H. Morgan Department of Radiology and \\ Radiological Sciences, Johns Hopkins University, \\ Baltimore, Maryland, United States \\ 4 Welch Medical Library, Johns Hopkins University, \\ Baltimore, Maryland, United States \\ 5 Division of Gastroenterology and Hepatology, Johns \\ Hopkins Medical Institutions, Baltimore, Maryland, \\ United States
}

Mohamad Aghaie Meybodi' ${ }^{1}$, Bashar J. Qumseya², Delaram Shakoor ${ }^{3}$, Katie Lobner ${ }^{4}$, Kia Vosoughi $^{5}$, Yervant

submitted 5.6.2018

accepted after revision 29.10.2018

\author{
Bibliography \\ DOI https://doi.org/10.1055/a-0812-1458 | \\ Endoscopy International Open 2019; 07: E322-E329 \\ (c) Georg Thieme Verlag KG Stuttgart · New York \\ ISSN 2364-3722
}

Corresponding author
Mouen Khashab, MD Associated Professor of Medicine,
Director of Therapeutic Endoscopy, Division of
Gastroenterology and Hepatology, Johns Hopkins Medical
Institutions, 1800 Orleans St, Sheikh Zayad 7E Rm 7125G,
Baltimore, MD 21224
Fax:+1-443-739-5219
mkhasha1@jhmi.edu

\section{Introduction}

Gastroparesis is a chronic motility disorder of the stomach characterized by pyloric dysfunction, antral hypomotility and/ or poor fundic accommodation [1]. Several conditions and diseases such as vagal nerve injury following surgery, diabetes mellitus, neurologic diseases, and gastrointestinal infections could induce neuromuscular dysfunction and produce symp-
ABSTRACT

Background and aim Clinical management of patients with gastroparesis is challenging. Prior pyloric targeted procedures are either invasive or have questionable longterm efficacy. Gastric per-oral endoscopic myotomy (GPOEM) has been recently introduced as a minimally invasive approach. In this review, we performed a meta-analysis to evaluate the feasibility and efficacy of this technique in the management of patients with refractory gastroparesis.

Methods PubMed, Embase, and Scopus databases were searched to identify relevant studies published through May 2018. Weighted pool rates (WPR) of the clinical resolution were calculated. Pooled values of Gastroparesis Cardinal Symptom Index (GCSI) before and after the procedure were compared. Pooled difference in means comparing gastric emptying before and after the procedure was calculated. Fixed or random effect model was used according to the level of heterogeneity.

Results Seven studies with 196 patients were included in the meta-analysis. The mean value of procedure duration was 69.7 (95\% confidence interval [95\% Cl]: $39-99$ minutes) and average estimate of hospital stay was 1.96 (95\% Cl: $1.22-2.95)$ days. The WPR for clinical success was $82 \%$ ( $95 \% \mathrm{Cl}: 74 \%-87 \%, \mathrm{I}^{2}=0$ ). Compared with pre-procedure GCSI values, mean values of GCSI were reduced significantly at 5 days $\left(-1.57\right.$ (95\% Cl:-2.2,-0.9), $\left.\mathrm{I}^{2}=80 \%\right)(P<0.001)$. Mean values of gastric emptying were significantly decreased $2-3$ months after the procedure $(-22.3$ (95\% Cl: -32.9, - 11.6), $\left.\left.\right|^{2}=67 \%\right)(P<0.05)$.

Conclusion Due to the high rate of clinical success and low rate of adverse events, G-POEM should be considered in management of refractory gastroparesis. 
them less favorable [7]. Endoscopic interventions including intra-pyloric injection of botulinum toxin, endoscopic gastrojejunostomy, and transpyloric stenting have also been described [8].

Based on positive results with pylorus-dedicated procedures and the success of per-oral endoscopic myotomy (POEM) in management of esophageal achalasia, a minimally invasive method called per-oral pyloromyotomy (POP) or gastric POEM (G-POEM) recently has been introduced [9-10]. This novel technique employs principles of esophageal POEM and was first reported by Khashab et al. in 2013 [10]. Over the last few years, several observational studies and case reports have described promising results of G-POEM in treatment of patients with refractory gastroparesis [11-19]. These recently published studies were intended to describe this new technique as a feasible and effective approach for management of patients with refractory gastroparesis. Nevertheless, owing to the novelty of this technique, the published studies had small sample sizes and short follow-ups. Also, this skill-dependent technique has been done by highly experienced endoscopists and there is no consensus on the efficacy and safety of the procedure. Thus, we aimed to perform a meta-analysis assessing the success rate of G-POEM, its adverse events (AEs) and the results of patients' follow-up scintigraphic studies.

\section{Methods}

The current meta-analysis was performed following the guidelines of the Preferred Reporting Items for Systematic Reviews and Meta-Analyses (PRISMA) [20] and meta-analysis of observational studies in epidemiology (MOOSE) [21].

\section{Literature search and study selection}

The study protocol was elaborated and approved by the investigators. A comprehensive literature search was developed by an experienced medical reference librarian (K.L) and the subsequent literature search was conducted by two independent investigators (MA.M, D.S). To find relevant publications, MEDLINE, Embase and Scopus databases were searched through May 1, 2018. The MeSH and keyword search terms included: "Gastric per-oral endoscopy myotomy," "G-POEM," “per-oral pyloromyotomy," and "gastroparesis". All identified records were screened based on their title and abstract and the eligible articles were selected to be evaluated at the level of full text. Only English language articles were included. In addition, the bibliography of eligible articles was reviewed to identify more relevant studies.

\section{Inclusion and exclusion criteria}

Inclusion criteria were established by two authors (MAM, MAK) and were determined as studies that described performing GPOEM on patients with refractory gastroparesis (persistent symptoms refractory to medical therapy or Gastroparesis Cardinal Symptom Index (GCSI) >1.5 for more than 6 months). We intended to identify randomized clinical trials (RCTs) or observational studies that reported clinical success rate and $\mathrm{GSCl}$ or gastric emptying scan (GES) before and after G-POEM. Clini- cal success rate was defined as statistically significant improvement in the mean GCSI.

Exclusion criteria were:

- Studies performed on animal subjects

- Individual case reports or case series with fewer than 5 patients

- Published abstracts

- Review articles, technical and investigative studies that did not report original data for clinical outcomes

All eligible articles were downloaded into EndNote 7.0 (Thomson ISI ResearchSoft, Philadelphia, Pennsylvania, United States), and duplicate studies were removed. Relevant articles were identified for review at the level of full text according to their titles and abstracts. Studies were selected for the final inclusion if they met all the inclusion criteria. The whole process of literature search, identification of relevant articles and fulltext study review were performed by two investigators independently. The decision for the final inclusion was achieved by joint consensus between two investigators (MA.M, DS).

\section{Data extraction and quality assessment}

Data were extracted by two independent investigators (M.AM, D.S) from included articles using a predesigned extraction data form. Study design, year of publication, number of patients, age, clinical success rate, GCSI before and after procedure, GES before and after procedure, etiology of gastroparesis, length of procedure, length of hospital stay, myotomy length, and adverse events were extracted. Two independent investigators (M.AM, DS) conducted quality assessment by using the National Institutes of Health (NIH) quality assessment tool for before - after studies with no control group [18]. Any discrepancy between investigators was discussed and a joint consensus was achieved.

\section{Statistical analysis and data synthesis}

Efficacy and feasibility of G-POEM were considered as the primary outcomes of interest in this study. Weighted pool rates of clinical success with their corresponding $95 \%$ confidence intervals $(\mathrm{Cl})$ were calculated and the corresponding forest plot was drawn.

Secondary outcomes of interest of this study included:

- Pooled difference in mean values of GCSI before and after the procedure.

- Pooled difference in mean value of GES before and after the procedure.

Paired $t$ test was used to compare before and after procedure values in each study.

Heterogeneity across studies was evaluated by Cochran's $Q$ test and $\mathrm{I}^{2}$ [22]. $P<0.1$ for the Cochran's $Q$ test was considered statistically significant for presence of heterogeneity. The $\mathrm{I}^{2}$ score values of $0 \%$ to $50 \%, 50 \%$ to $75 \%$, and $75 \%$ to $100 \%$ were considered as low, moderate, and high heterogeneity, respectively [23]. When heterogeneity was low, fixed effect model was applied and if moderate or high level of heterogeneity was observed, DerSimonian - Laird random-effects model of meta-analysis were applied [24-25]. 


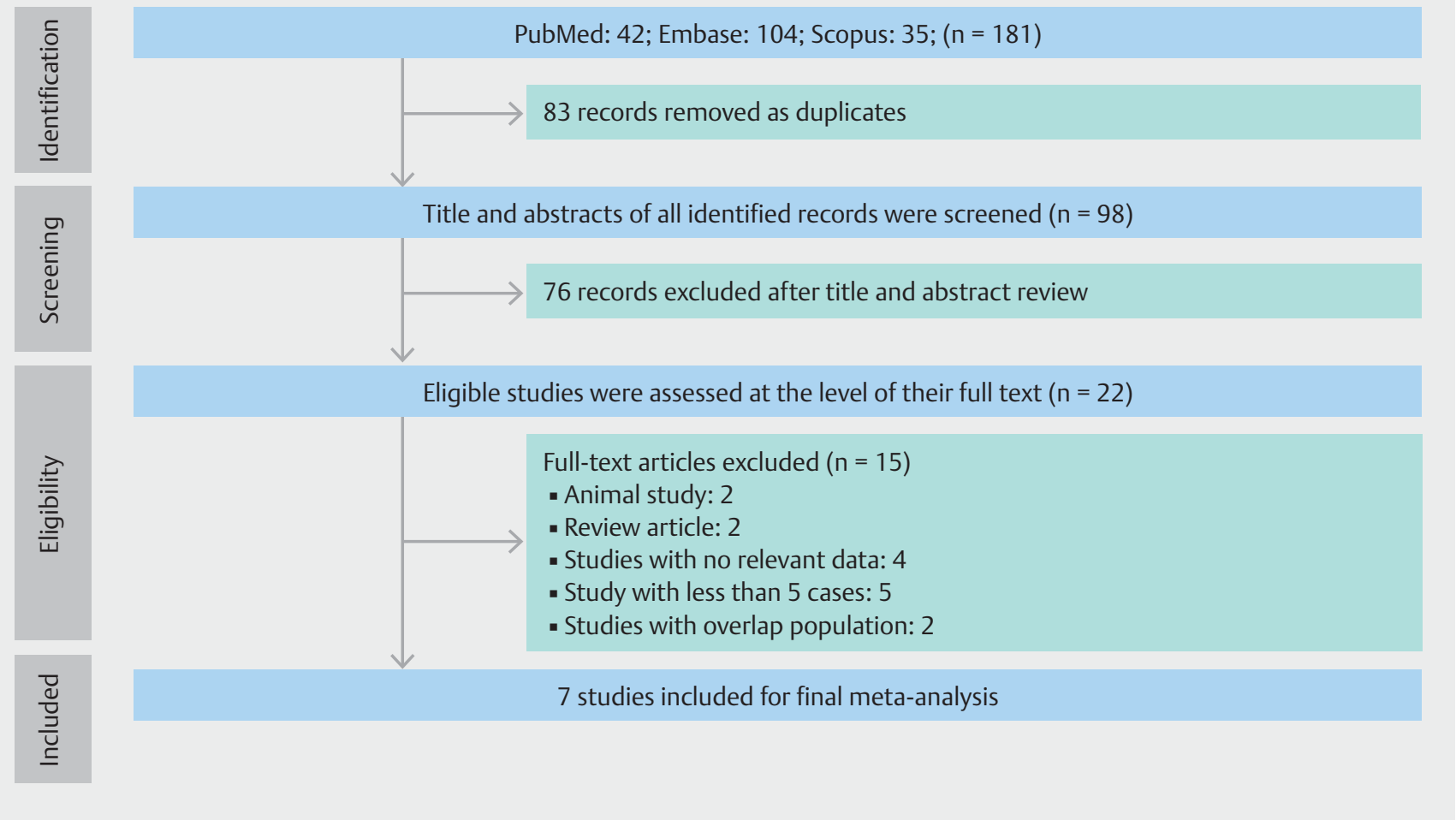

Fig. 1 PRISMA flowchart.

Publication bias was evaluated by Egger's test and visual evaluation of obtained funnel plots. If publication bias was found, Duval and Tweedie's "trim and fill" test was used to account for the possibly missing studies.

All analysis was performed by Comprehensive Meta-Analysis software (version 3.0; Biostat; Englewood, New Jersey, United States).

\section{Results}

\section{Literature search}

Our search strategy identified 42 records from PubMed, 104 records from Embase, and 35 records from Scopus. After removal of duplicates, 98 articles were screened based on their title and abstract and 76 records were excluded. Full texts of 22 studies were reviewed for the final inclusion. One study was not selected for the final inclusion due to the fact that it was performed under guidance of laparoscopy [17]. We excluded two studies due to population overlap [11-12]. Finally, seven studies with a total 196 patients with refractory gastroparesis were included in this meta-analysis. Two studies $[11,15]$ were prospective and five studies [13-14, 16,18-19] were retrospective. The search strategy and the process of study selection are described in a PRISMA flowchart ( Fig. 1 ).

\section{Study characteristics and quality assessment}

Regarding the etiology of gastroparesis among these 196 patients, idiopathic was the most prevalent cause, present in 83 cases $(42.3 \%), 51$ cases (26\%) were post-surgical, and 56 cases
(28.5\%) were diabetic. Six patients (3\%) had gastroparesis due to other etiologies such as infection and scleroderma. Due to small number of patients in each group, cumulative clinical response was analyzed. Patients' duration of follow-up ranged between 1 and 18 months.

In six studies [13-16,18-19] routine G-POEM was performed as described by Khashab et al. [10], while in one study [11], fluoroscopy-guided G-POEM was performed. Demographic data, technical information and reported complications are detailed in $>$ Table 1. Duration of procedure was reported in six studies $[13-16,18-19]$ with a mean of 69.7 minutes $(95 \%$ Cl: $39-99)$, Cochern $Q$ test $P<0.001, I^{2}=97 \%$, random effect model. Eager's test revealed no publication bias (two-sided $P=$ $0.29)$. The pooled average hospital stay was 1.96 days $(95 \% \mathrm{Cl}$ : $0.98-3.02)$ and was reported in four studies $[14-16,19] P<$ $0.001, I^{2}=96 \%$ random effect model. Egger's test demonstrated low risk of publication bias (two-sided $P=0.35$ ).

Based on NIH quality assessment, three studies [13-14,18] had good quality, and the other four studies [11,15-16,19] were of fair quality ( $\vee$ Table 2 ).

\section{Meta-analysis}

Primary outcome

Overall, the technical success rate was $100 \%$. Regarding the primary outcome of interest, five studies [13-15, 18 - 19] reported clinical success rate. One study [14] defined clinical success as improvement in symptoms without recurrent hospitalization. Another study [15] reported clinical success subjectively 


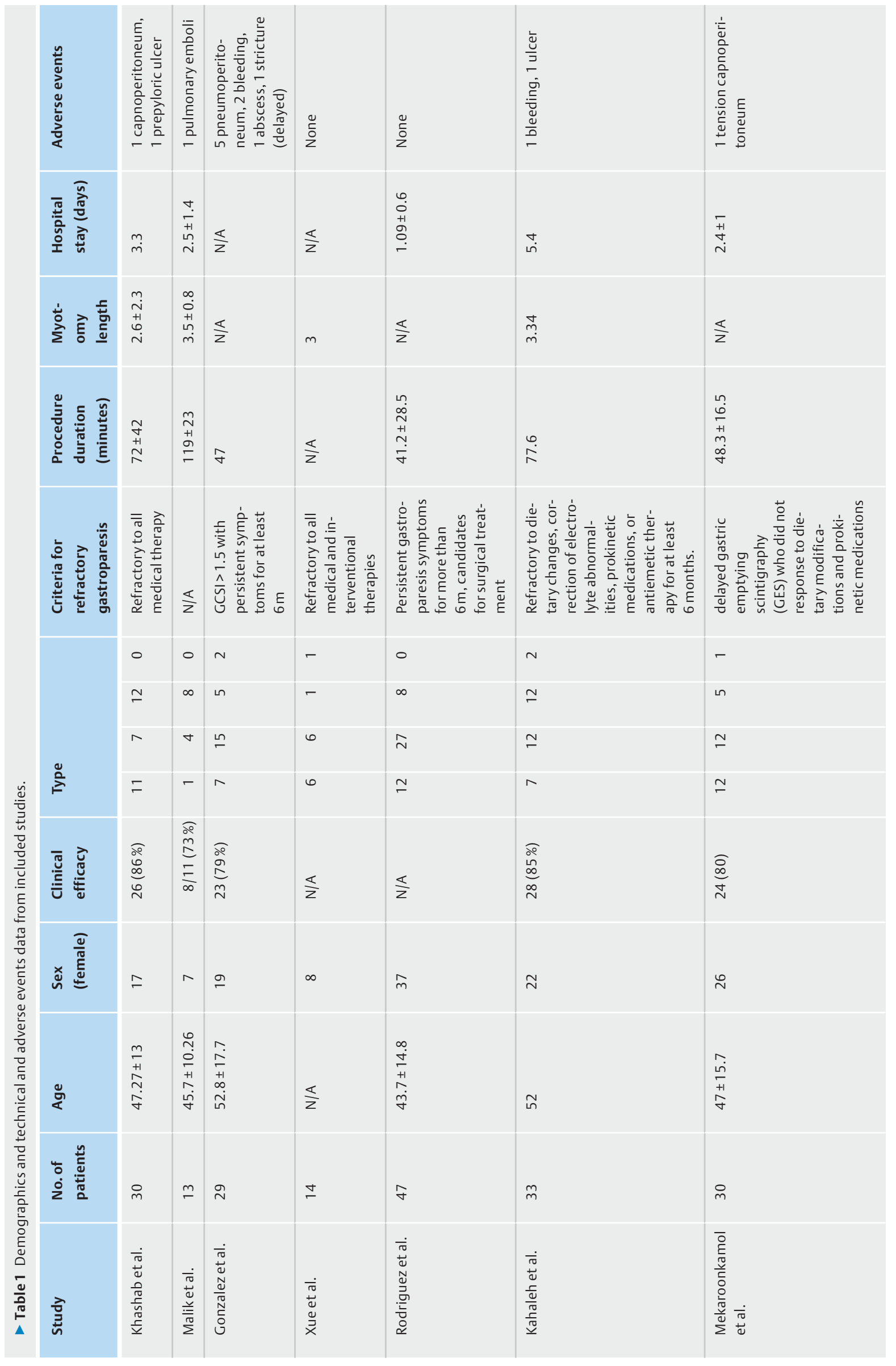


- Table 2 Quality assessment of studies with NIH quality assessment tool for before - after studies with no control group.

\begin{tabular}{|c|c|c|c|c|c|c|c|}
\hline Criterion & $\begin{array}{l}\text { Khashab } \\
\text { et al. } \\
2017\end{array}$ & $\begin{array}{l}\text { Malik et } \\
\text { al. } 2018\end{array}$ & $\begin{array}{l}\text { Gonza- } \\
\text { lez et al. } \\
2017\end{array}$ & $\begin{array}{l}\text { Xue et } \\
\text { al. } \\
2017\end{array}$ & $\begin{array}{l}\text { Rodriguez } \\
\text { et al. } \\
2017\end{array}$ & $\begin{array}{l}\text { Kahaleh } \\
\text { et al. } \\
2018\end{array}$ & $\begin{array}{l}\text { Mekar- } \\
\text { oonkamol } \\
\text { et al. } \\
2018\end{array}$ \\
\hline $\begin{array}{l}\text { 1. Was the study question or objective } \\
\text { clearly stated? }\end{array}$ & Yes & Yes & Yes & Yes & Yes & Yes & Yes \\
\hline $\begin{array}{l}\text { 2. Were eligibility/selection criteria for } \\
\text { the study population prespecified and } \\
\text { clearly described? }\end{array}$ & Yes & Yes & Yes & Yes & Yes & Yes & Yes \\
\hline $\begin{array}{l}\text { 3. Were the participants in the study } \\
\text { representative of those who would be } \\
\text { eligible for the test/service/interven- } \\
\text { tion in the general or clinical population } \\
\text { of interest? }\end{array}$ & Yes & Yes & Yes & Yes & Yes & Yes & Yes \\
\hline $\begin{array}{l}\text { 4. Were all eligible participants that } \\
\text { met the prespecified entry criteria en- } \\
\text { rolled? }\end{array}$ & Yes & Yes & Yes & Yes & Yes & Yes & No \\
\hline $\begin{array}{l}\text { 5. Was the sample size sufficiently large } \\
\text { to provide confidence in the findings? }\end{array}$ & No & No & No & No & No & No & No \\
\hline $\begin{array}{l}\text { 6. Was the test/service/intervention } \\
\text { clearly described and delivered consis- } \\
\text { tently across the study population? }\end{array}$ & Yes & No & Yes & Yes & Yes & Yes & Yes \\
\hline $\begin{array}{l}\text { 7. Were the outcome measures prespe- } \\
\text { cified, clearly defined, valid, reliable, } \\
\text { and assessed consistently across all } \\
\text { study participants? }\end{array}$ & Yes & Yes & Yes & Yes & Yes & Yes & Yes \\
\hline $\begin{array}{l}\text { 8. Were the people assessing the out- } \\
\text { comes blinded to the participants' ex- } \\
\text { posures/interventions? }\end{array}$ & No & No & No & No & No & No & No \\
\hline $\begin{array}{l}\text { 9. Was the loss to follow-up after base- } \\
\text { line } 20 \% \text { or less? Were those lost to fol- } \\
\text { low-up accounted for in the analysis? }\end{array}$ & Yes & Yes & Yes & Yes & No & Yes & Yes \\
\hline $\begin{array}{l}\text { 10. Did the statistical methods examine } \\
\text { changes in outcome measures from } \\
\text { before to after the intervention? Were } \\
\text { statistical tests done that provided p } \\
\text { values for the pre-to-post changes? }\end{array}$ & Yes & Yes & Yes & Yes & Yes & Yes & Yes \\
\hline $\begin{array}{l}\text { 11. Were outcome measures of interest } \\
\text { taken multiple times before the inter- } \\
\text { vention and multiple times after the in- } \\
\text { tervention (i. e., did they use an inter- } \\
\text { rupted time-series design)? }\end{array}$ & Yes & Yes & Yes & No & Yes & Yes & Yes \\
\hline $\begin{array}{l}\text { 12. If the intervention was conducted at } \\
\text { a group level (e. g., a whole hospital, a } \\
\text { community, etc.) did the statistical a- } \\
\text { nalysis take into account the use of in- } \\
\text { dividual-level data to determine effects } \\
\text { at the group level? }\end{array}$ & $\mathrm{N} / \mathrm{A}$ & $\mathrm{N} / \mathrm{A}$ & $\mathrm{N} / \mathrm{A}$ & $\mathrm{N} / \mathrm{A}$ & $\mathrm{N} / \mathrm{A}$ & $\mathrm{N} / \mathrm{A}$ & $\mathrm{N} / \mathrm{A}$ \\
\hline Results & Good & Fair & Good & Fair & Fair & Good & Fair \\
\hline
\end{tabular}

by using Clinical Patient Grading Assessment Score (CPGAS). The remaining studies $[11,13,16,18-19]$ described clinical success as significant decrease in the GCSI after procedure. On fixed effects models, the weighted pooled rate (WPR) of clinical success of G-POEM was $82 \%(95 \% \mathrm{Cl}: 74 \%-87 \%), P=0.83, \mathrm{I}^{2}=0$
( $\triangleright$ Fig.2). Visual assessment of funnel plot and Egger's test demonstrated low risk of publication bias (two-sided $P=0.61$ ). 
Clinical success

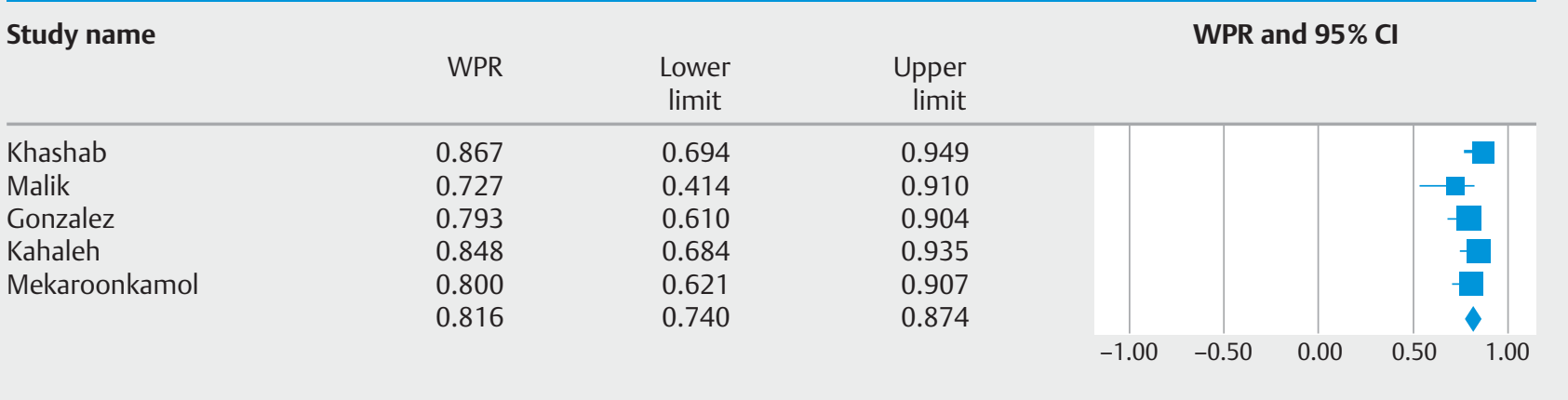

- Fig. 2 Forest plot displaying weighted pool rate for clinical success of G-POEM in refractory gastroparesis.

GCSI before and 5 days after the procedure

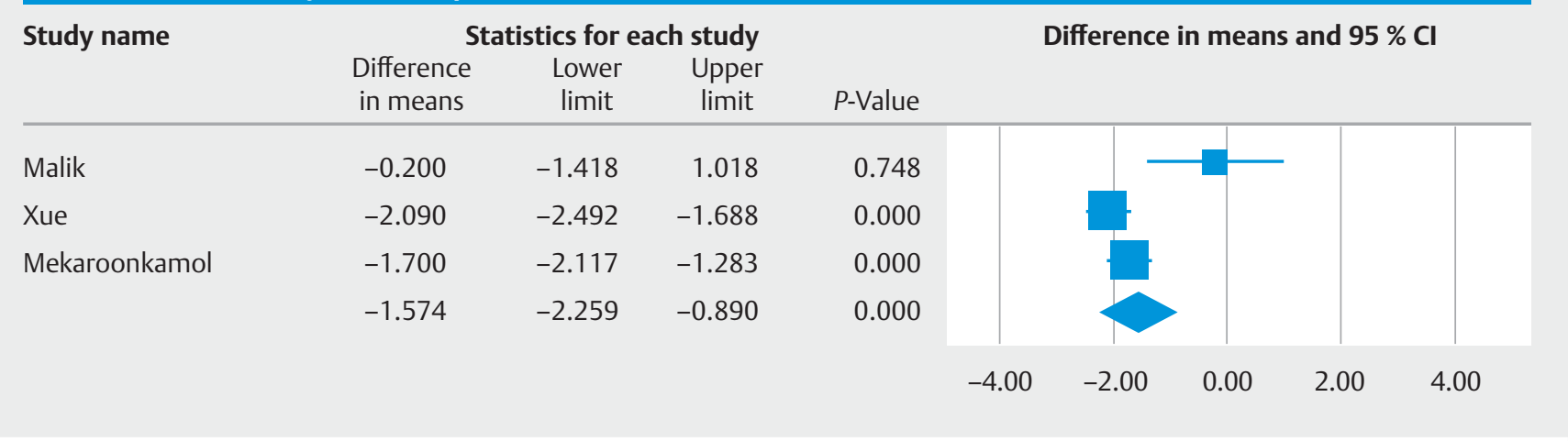

- Fig. 3 Forest plot displaying difference in means of GCSI before and 5 days after the procedure.

\section{Secondary outcomes}

For secondary outcomes of interest, the pooled difference in means of GCSI before and after procedure was calculated. Three studies $[11,15,19]$ reported mean values of GCSI 5 days after the procedure. The pooled mean difference in GCSI following the procedure was statistically significant - 1:57 [95\% $\mathrm{Cl}:-2.2,-0.9 ; P<0.001]$, Cochrane $\mathrm{Q}$ test $P=0.01, \mathrm{I}^{2}=77 \%$, random effect model ( $\triangleright$ Fig.3). Although the heterogeneity was high, all studies reported decrease in values of GCSI following G-POEM. Egger's tests did not find any publication bias ( $P=$ 0.62 , two-sided). Mean difference of GCSI 1 month following GPOEM $-2.35 \pm 0.47$ and $-1.7 \pm 0.42$, which was reported by Gonzalez et al. [13] and Mekaroonkamol et al. [19], respectively. The mean difference between $\mathrm{GSCl}$ before and 3 months after the procedure was reported by Gonzalez et al. [13] (-2.3 $\pm 0.55)$ and Rodriguez et al. [16] (-1.3 \pm 0.46$)$.

The average percentage of gastric retention 4 hours after a solid meal on GES before and 2 to 3 months after the procedure were reported by 5 studies $[13-16,19]$. It was decreased significantly $(P<0.001)$ and difference in mean values of GES was 22.3 (95\% Cl:-32.9,-11.6), Cochran Q test $P=0.01, I^{2}=67 \%$, random effect model ( $\triangleright$ Fig.4). Egger's test did not show any publication bias $(P=0.72$, two-sided $)$.
Adverse events

All seven articles $[11,13-16,18-19]$ reported post-procedure AEs. Twelve AEs were reported in 196 patients. Capnoperitoneum was the most common. It happened in seven cases and was managed with needle decompression. Peptic ulcer and bleeding occurred in two patients. One case of pulmonary emboli, one case of abscess, and one case of stricture were also reported. No mortality was reported due to G-POEM.

\section{Discussion}

Since the first report of human G-POEM in 2013 [10], a few studies have described the technical feasibility and short-term outcomes of this treatment modality [11-19]. The findings of our meta-analysis suggest that G-POEM could be considered as an effective treatment for management of patients with refractory gastroparesis. In all studies, the technical success rate was $100 \%$. Based on a systematic review and meta-analysis, we found a very high clinical success rate.

While many surgical options including pyloroplasty have been described for management of patients with refractory gastroparesis [26-27], their results have been variable with a high rate of complications and recurrence of patient symptoms [27]. Gastric electrical stimulation has been described as one of 
Gastric retention 4 hours after solid meal on GES before and after the procedure

\begin{tabular}{lcrrr} 
Study name & \multicolumn{4}{c}{ Statistics for each study } \\
& $\begin{array}{l}\text { Difference } \\
\text { in means }\end{array}$ & $\begin{array}{c}\text { Lower } \\
\text { limit }\end{array}$ & $\begin{array}{c}\text { Upper } \\
\text { limit }\end{array}$ & $P$-Value \\
\hline Khashab & -20.000 & -30.000 & -9.974 & 0.000 \\
Malik & -16.000 & -38.182 & 6.182 & 0.157 \\
Gonzalez & -12.000 & -32.527 & 8.572 & 0.252 \\
Rodriguez & -16.800 & -27.152 & -6.448 & 0.001 \\
Mekaroonkamol & -40.800 & -52.424 & -29.176 & 0.000 \\
& -22.308 & -32.944 & -11.671 & 0.000
\end{tabular}

Difference in means and $95 \% \mathrm{Cl}$

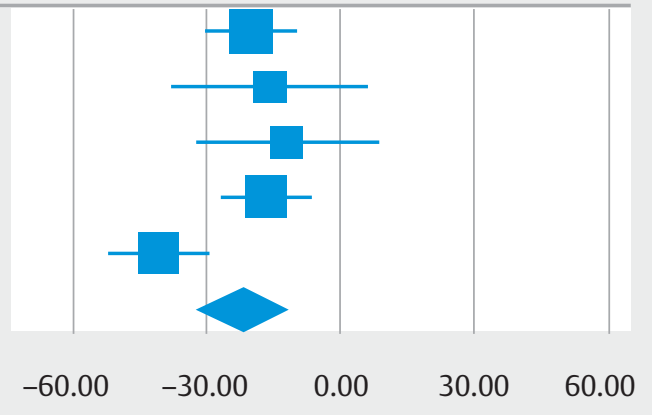

Fig. 4 Forest plot displaying difference in means of GES before and after the procedure.

the most popular surgical techniques for management of patients with gastroparesis [28]. Though this technique has been shown to significantly improve symptoms in patients with diabetic gastroparesis, that was not observed in patients with other etiologies. One clinical trial that evaluated the efficacy of gastric electrical stimulation in 33 patients with diabetic and idiopathic gastroparesis reported no significant improvement [29]. Furthermore, device-related complications such as lead migration, infection, bowel obstruction, and perforation were also reported in several studies [26-27]. There has been a trend toward less invasive, more efficient alternative options such as endoscopic implantation of gastric electrical stimulation [28]. While initial results have been promising, further larger studies are required to evaluate the outcomes of this technique.

The promising results of our meta-analysis could be attributed to the underlying mechanisms of gastroparesis. A subset of patients with gastroparesis have functional outlet obstruction due to pyloric dysfunction, spasm, or fibrosis [30]. Thus, it is assumed that therapeutic interventions specific to the pylorus could yield satisfactory outcomes. A number of therapeutic procedures directed at the pylorus have been described. For instance, intrapyloric injection of botulinum toxin has been applied and two placebo-controlled studies evaluated the outcome of this technique in management of patients with gastroparesis [31-32]. However, the results were not satisfactory due to short duration of action and suboptimal efficacy. According to The American College of Gastroenterology, this technique is not recommended for management of patients with gastroparesis and further investigations are required to assess the efficacy of this technique in a particular subset of patients with documented pylorospasm.

Transpyloric stenting has also been introduced as another pylorus-directed technique. In a retrospective case series, this technique was performed on 30 patients with refractory gastroparesis [33]. The authors reported that clinical response was significantly lower in patients with pain than those patients with nausea and vomiting. Furthermore, stent migration was a common complication, which occurred in at least $48 \%$ of patients even after stent suturing. This technique is not considered definitive therapy in these patients.

This is the first meta-analysis that evaluated the outcome of GPOEM in patients with refractory gastroparesis. We performed a comprehensive literature search and excluded published abstracts, as there are usually discrepancies between full publication and the published abstracts. Based on the findings of our meta-analysis and comparing our results with other management options for gastroparesis, it could be assumed that GPOEM could serve as a potentially ideal technique with low risk of complications. However, it should be noted that results of our study are weakened by limitations inherent to the included studies. G-POEM is a relatively new technique and the studies that reported the outcome of this procedure have short follow-up duration. Therefore, we cannot not provide high-level evidence regarding the durability of this technique in offering long-term symptom relief. Furthermore, included studies were relatively small. Although we did not observe a significant level of heterogeneity in our primary outcome measure, we noted a high level of heterogeneity in all of our secondary outcome measures. This finding could be attributed to different inclusion criteria in the studies. Included studies implemented distinct criteria to define clinical success rate. Moreover, patients with gastroparesis have various etiologies as well as symptoms and we could not categorize our outcomes based on these etiologies, owing to small sample size of study populations and limited available data. For objective assessment of clinical response, GCSI was reported at baseline, 5 days, 1 month, and 3 months after the procedure and GES was evaluated at baseline and 2 to 3 months after the procedure. Finally, included studies have been performed by experienced endoscopists and this might affect the generalizability of our findings. 


\section{Conclusion}

The findings of our meta-analysis suggest that G-POEM is an effective therapeutic intervention for management of patients with refractory gastroparesis in terms of clinical response and scintigraphic studies. Large controlled trials are required to identify the subset of patients who would benefit the most from this technique.

\section{Competing interests}

Dr. Khashab is a consultant for Boston Scientific, Olympus and Medtronic and is on the medical advisory board for Boston Scientific and Olympus.

\section{References}

[1] Parkman HP, Hasler WL, Fisher RS. American Gastroenterological Association technical review on the diagnosis and treatment of gastroparesis. Gastroenterology 2004; 127: $1592-1622$

[2] Camilleri M, Parkman HP, Shafi MA et al. Clinical guideline: management of gastroparesis. Am J Gastroenterol 2013; 108: 18 - 37; quiz 38

[3] Hasler WL. Gastroparesis: pathogenesis, diagnosis and management. Nat Rev Gastroenterol Hepatol 2011; 8: 438-453

[4] Wang YR, Fisher RS, Parkman HP. Gastroparesis-related hospitalizations in the United States: trends, characteristics, and outcomes, 1995-2004. Am J Gastroenterol 2008; 103: 313 - 322

[5] Sangnes DA, Søfteland E, Biermann M et al. Gastroparesis-causes, diagnosis and treatment. Tidsskr Nor Laegeforen 2016; 136: 822 - 826

[6] Jones MP, Maganti K. A systematic review of surgical therapy for gastroparesis. Am J Gastroenterol 2003; 98: 2122-2129

[7] Ahuja NK, Clarke JO. Pyloric therapies for gastroparesis. Curr Treat Options Gastroenterol 2017; 15: 230-240

[8] Coleski R, Anderson MA, Hasler WL. Factors associated with symptom response to pyloric injection of botulinum toxin in a large series of gastroparesis patients. Dig Dis Sci 2009; 54: 2634-2642

[9] Awaiz A, Yunus RM, Khan S et al. Systematic review and meta-Analysis of Perioperative Outcomes of Peroral Endoscopic Myotomy (POEM) and laparoscopic heller myotomy (LHM) for achalasia. Surg Laparosc Endosc Percutan Tech 2017; 27: $123-131$

[10] Khashab MA, Stein E, Clarke JO et al. Gastric peroral endoscopic myotomy for refractory gastroparesis: first human endoscopic pyloromyotomy (with video). Gastrointest Endosc 2013; 78: 764 - 768

[11] Dacha S, Mekaroonkamol P, Li L et al. Outcomes and quality-of-life assessment after gastric per-oral endoscopic pyloromyotomy (with video). Gastrointestinal endoscopy 2017; 86: 282-289

[12] Gonzalez J-M, Lestelle V, Benezech A et al. Gastric per-oral endoscopic myotomy with antropyloromyotomy in the treatment of refractory gastroparesis: clinical experience with follow-up and scintigraphic evaluation (with video). Gastrointest Endosc 2017; 85: 132 - 139

[13] Gonzalez J, Benezech A, Vitton V et al. G-POEM with antro-pyloromyotomy for the treatment of refractory gastroparesis: mid-term follow-up and factors predicting outcome. Aliment Pharmacol Ther 2017; 46: $364-370$

[14] Khashab MA, Ngamruengphong S, Carr-Locke D et al. Gastric per-oral endoscopic myotomy for refractory gastroparesis: results from the first multicenter study on endoscopic pyloromyotomy (with video). Gastrointest Endosc 2017; 85: 123-128

[15] Malik Z, Kataria R, Modayil R et al. Gastric Per Oral Endoscopic Myotomy (G-POEM) for the treatment of refractory gastroparesis: early experience. Dig Dis Sci 2018; 63: 2405-2412

[16] Rodriguez JH, Haskins IN, Strong AT et al. Per oral endoscopic pyloromyotomy for refractory gastroparesis: initial results from a single institution. Surg Endosc 2017; 31: 5381-5388

[17] Shlomovitz E, Pescarus R, Cassera MA et al. Early human experience with per-oral endoscopic pyloromyotomy (POP). Surg Endosc 2015; 29: $543-551$

[18] Quality Assessment Tool for Before-After Studies with No Control Group. National Institutes of Health Web site. 2014: https://www. nhlbi.nih.gov/health-topics/study-quality-assessment-tools

[19] Mekaroonkamol P, Dacha S, Wang L et al. Gastric peroral endoscopic pyloromyotomy reduces symptoms, increases quality of life, and reduces healthcare usage for patients with gastroparesis. Clin Gastroenterol Hepatol 2018: doi:10.1016/j.cgh.2018.04.016

[20] Liberati A, Altman DG, Tetzlaff J et al. The PRISMA statement for reporting systematic reviews and meta-analyses of studies that evaluate health care interventions: explanation and elaboration. PLoS Med 2009; 6: e1000100

[21] Stroup DF, Berlin JA, Morton SC et al. Meta-analysis of observational studies in epidemiology: a proposal for reporting. JAMA 2000; 283: $2008-2012$

[22] Higgins JP, Thompson SG, Deeks JJ et al. Measuring inconsistency in meta-analyses. BMJ 2003; 327: 557

[23] Armitage P, Berry G, Matthews JNS. Statistical methods in medical research. John Wiley \& Sons; 2008

[24] DerSimonian R, Laird N. Meta-analysis in clinical trials. Control Clin Trials 1986; 7: 177-188

[25] Riley RD, Higgins JP, Deeks JJ. Interpretation of random effects metaanalyses. BMJ 2011; 342: d549

[26] Waseem S, Moshiree B, Draganov PV. Gastroparesis: current diagnostic challenges and management considerations. World J Gastroenterol 2009; 15: 25-37

[27] Sarosiek I, Davis B, Eichler E et al. Surgical approaches to treatment of gastroparesis: gastric electrical stimulation, pyloroplasty, total gastrectomy and enteral feeding tubes. Gastroenterol Clin North Am 2015; 44: $151-167$

[28] Navas CM, Patel NK, Lacy BE. Gastroparesis: medical and therapeutic advances. Dig Dis Sci 2017; 62: 2231 - 2240

[29] Abell T, McCallum R, Hocking M et al. Gastric electrical stimulation for medically refractory gastroparesis. Gastroenterology 2003; 125 : $421-428$

[30] Khashab MA, Ngamruengphong S, Carr-Locke D et al. Gastric per-ora endoscopic myotomy for refractory gastroparesis: results from the first multicenter study on endoscopic pyloromyotomy (with video). Gastrointest Endosc 2017; 85: 123-128

[31] Arts J, Holvoet L, Caenepeel P et al. Clinical trial: a randomized-controlled crossover study of intrapyloric injection of botulinum toxin in gastroparesis. Aliment Pharmacol Ther 2007; 26: 1251-1258

[32] Friedenberg FK, Palit A, Parkman HP et al. Botulinum toxin A for the treatment of delayed gastric emptying. Am J Gastroenterol 2008; 103: 416

[33] Khashab MA, Besharati S, Ngamruengphong S et al. Refractory gastroparesis can be successfully managed with endoscopic transpyloric stent placement and fixation (with video). Gastrointest Endosc 2015; 82: $1106-1109$ 